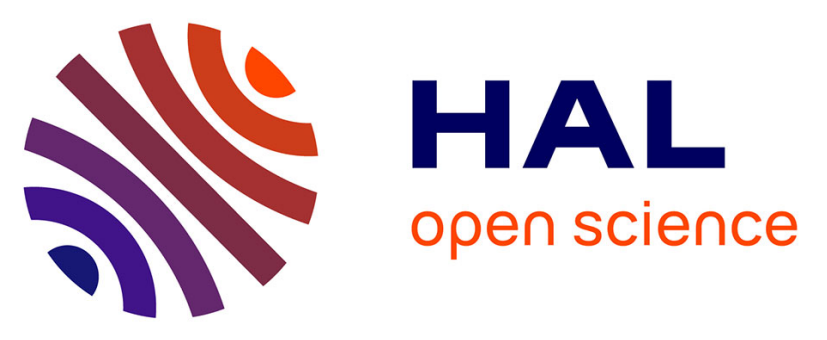

\title{
LSP2-9166, an orthosteric mGlu4 and mGlu7 receptor agonist, reduces cocaine self-administration under a progressive ratio schedule in rats
}

David de Sa Nogueira, Romain Bourdy, Dominique Filliol, Cyril Quessada, Isabelle Mccort, Francine Acher, Jean Zwiller, Pascal Romieu, Katia Befort

\section{To cite this version:}

David de Sa Nogueira, Romain Bourdy, Dominique Filliol, Cyril Quessada, Isabelle Mccort, et al.. LSP2-9166, an orthosteric mGlu4 and mGlu7 receptor agonist, reduces cocaine selfadministration under a progressive ratio schedule in rats. Neuroscience Letters, 2020, pp.135603. 10.1016/j.neulet.2020.135603 . hal-03359144

\author{
HAL Id: hal-03359144 \\ https://hal.science/hal-03359144
}

Submitted on 29 Sep 2021

HAL is a multi-disciplinary open access archive for the deposit and dissemination of scientific research documents, whether they are published or not. The documents may come from teaching and research institutions in France or abroad, or from public or private research centers.
L'archive ouverte pluridisciplinaire HAL, est destinée au dépôt et à la diffusion de documents scientifiques de niveau recherche, publiés ou non, émanant des établissements d'enseignement et de recherche français ou étrangers, des laboratoires publics ou privés. 


\section{LSP2-9166, an orthosteric mGlu4 and mGlu7 receptor agonist, reduces cocaine self-administration under a progressive ratio schedule in rats}

David de sa Nogueira ${ }^{1}$, Romain Bourdy ${ }^{1}$, Dominique Filliol ${ }^{1}$, Cyril Quessada ${ }^{1,2}$, Isabelle McCort-Tranchepain ${ }^{3}$, Francine Acher ${ }^{3}$, Jean Zwiller ${ }^{1}$, Pascal Romieu ${ }^{1, \#}$, Katia Befort ${ }^{1, \#, *}$

\section{Affiliation}

${ }^{1}$ Université de Strasbourg, Laboratoire de Neurosciences Cognitives et Adaptatives (LNCA), Faculté de Psychologie, UMR 7364, CNRS 12 rue Goethe, F-67000 Strasbourg, France

${ }^{2}$ Université de Strasbourg, Inserm, UMR-S1118, 11 rue Humann, F-67000 Strasbourg, France

${ }^{3}$ Laboratoire de Chimie et Biochimie Pharmacologiques et Toxicologiques, CNRS

UMR8601, Université de Paris 45 rue des Saints-Pères, F-75270, Paris Cedex 6, France

Running title: Pharmacological activation of mGlu4 and mGlu7 receptors reduces cocaine motivation

Keywords: operant self-administration, LSP2-9166, Grm4, Grm7, cocaine, motivation

${ }^{\#}$ Co-last authors

*Corresponding author: Katia Befort

E-mail: katia.befort@unistra.fr

\section{Words}

Abstract: 210

Main text 2903

References 1164

Figure legends 260

Figures: 3 


\section{Abbreviations}

Amy: amygdala ; CPP: conditioned place preference ; DA: dopamine; DS: dorsal striatum ; G-protein coupled metabotropic glutamate: mGlu; HPC: hippocampus; LTP: long-term potentiation; PFC: prefrontal cortex; PR: progressive ratio; NAc: Nucleus Accumbens; SA: self-administration; VTA: ventral tegmental area 


\begin{abstract}
Cocaine addiction is a serious health issue in Western countries. Despite the regular increase in cocaine consumption across the population, there is no specific treatment for cocaine addiction. Critical roles for glutamate neurotransmission in the rewarding effects of psychostimulants as well as relapse have been suggested and accumulating evidence indicates that targeting mGlu group III receptors could represent a promising strategy to develop therapeutic compounds to treat addiction. In this context, the aim of our study was to examine the effect of LSP2-9166, a mGlu4/mGlu7 receptor orthosteric agonist, on the motivation for cocaine intake. We used an intravenous self-administration paradigm in male Wistar rats as a reliable model of voluntary drug intake. We first evaluated the direct impact of cocaine on Grm4 and Grm7 gene expression. Voluntary cocaine intake under a fixed ratio schedule of injections induced an increase of both mGlu4 and mGlu7 receptor transcripts in nucleus accumbens and hippocampus. We then evaluated the ability of LSP2-9166 to affect cocaine self-administration under a progressive ratio schedule of reinforcement. We found that this compound inhibits the motivation to obtain the drug, although it induced a hypolocomotor effect which could biais motivation index. Our findings demonstrate that mGlu group III receptors represent new targets for decreasing motivation to self-administer cocaine.
\end{abstract}




\section{Introduction}

Cocaine addiction is a chronic brain disease characterised by a high level of motivation for the drug and relapse in cocaine users [1]. Given the multifaceted health issue that results from this, including mortality and morbidity, research aimed at identifying the neurobiological mechanisms underlying cocaine's rewarding effects may lead to a better understanding of the processes involved in addiction and potential therapeutic strategies. It is well established that the dopamine (DA) neurotransmission system, particularly the mesolimbic pathway connecting the ventral tegmental area (VTA) to the nucleus accumbens (NAc), is crucial for the motivational component of behavior. This is classically measured in rodents using a progressive ratio (PR) schedule of cocaine self-administration (SA) [2]. In addition, emerging evidence points to a major role for glutamate in the progressive elaboration of cocaine-seeking behaviors [3] and glutamate levels are modified during relapse [4]. Glutamate acts on fast-acting ligand-gated ion channels, the ionotropic receptors, and slow-acting G-protein coupled metabotropic glutamate (mGlu) receptors. Three groups of mGlu receptors exist in the brain. Group I receptors (mGlu1/5 receptors) were the first to be demonstrated playing a role in drug dependence [5]. However, mnesic processes were also altered by these compounds [6]. Also, activation of group II mGlu receptors (mGlu2/3) reduces both seeking and taking behavior towards distinct drugs of abuse in rodents, through normalization of an altered glutamatergic neurotransmission induced by drug exposure [4]. However, activation of mGlu2/3 produced reduced food-seeking behaviors [7] and a decrease in cognitive performance $[8,9]$. Among receptors of group III, mGlu6 and mGlu8 receptors lack precise behavioral function, whereas $\mathrm{mGlu} 4 / 7$ receptors negatively control glutamate transmission and have been recently proposed as targets for several neurodegenerative and neuropsychiatric conditions $[10,11]$.

The mGlu4 and mGlu7 receptors are expressed in the basal ganglia and structures of the reward circuit $[12,13]$. L-AP4, an agonist of group III mGlu receptors, inhibits Glu and/or GABA release in key structures of the basal ganglia, such as striatum and globus pallidus [14, 15], therefore blocking cocaine-induced hyperlocomotion in rats [16]. Interestingly, a selective mGlu4 agonist, LSP1-2111, reduced the expression of cocaine sensitization [17]. A selective allosteric agonist of mGlu7 receptors, AMN082 [18], reduced cocaine SA [19] and altered both alcohol preference and intake [20]. Side-effects of this compound were observed, with a reduction of sucrose intake [21], and decreased locomotor activity at high doses [22]. 
Anti-depressive and anxyolitic effects were also observed and proposed to be linked to a rapid internalization process induced by AMN082 [23, 24].

The design of an orthosteric brain permeant subtype-selective ligand has facilitated new investigations. Indeed, LSP2-9166, a mGlu4/7 receptor orthosteric agonist [25], represents the most powerful orthosteric compound synthezised so far. Remarkably, it was recently shown to inhibit both morphine-induced place preference and reinstatement after extinction in mice [26], and ethanol intake in rats [27]. To complete this work on drug abuse, we first examined brain transcript levels for both mGlu4 and mGlu7 receptors following voluntary cocaine intake. We then examined whether the LSP2-9166 could modulate cocaine motivation in an intravenous (i.v.) SA procedure in rats.

\section{Materials and methods}

\section{Chemical compound}

LSP2-9166 was prepared according to an improved synthesis [25]. Briefly, Figure 1 illustrates these improvements from recently reported preparation of derivatives $[28,29]$ to avoid L-AP4 formation, a side product with selective and potent group III mGluR agonist activity. We first improved a straightforward synthesis of the $\mathrm{N}$-Boc-(S)-vinylglycine-O-tertbutyl ester from Boc-Asp-OtBu in two steps without intermediate purification affording a scale-up $[30,31]$. Purity was checked by NMR $\left({ }^{31} \mathrm{P}\right)$, with no detectable L-AP4, and confirmed before use by a pharmacological approach (ARPEGE Platform, Montpellier https://www.igf.cnrs.fr/index.php/fr/research-fr/facility-fr). Final deprotection under milder conditions led to the final product LSP2-9166 in higher yield, with a high purity.

\section{Subjects}

Male Wistar rats (Janvier Labs, France), aged five weeks and weighting 150-175 g upon arrival, were housed in standard home cages ( 5 rats/cage), under a reversed $12 \mathrm{~h}$ light/dark cycle (lights on at 7pm), with water and food ad libitum. All procedures involving animal care were conducted in compliance with current laws and policies, validated by a Comité d'Ethique en Expérimentation Animale (CREMEAS) and authorised by the Ministère de 1'Enseignement Supérieur, de la Rechercher et de 1'Innovation (APAFIS\#70502016093016163350). Eighteen rats were used for the molecular study and 69 for the SA procedure and locomotor activity. 


\section{Pharmacological treatment}

Cocaine hydrochloride (Cooper, France) solution was adjusted with $0.9 \% \mathrm{NaCl}$ to infuse an i.v. dose of 0.33 or $0.5 \mathrm{mg} / \mathrm{kg} /$ injection for SA and $1.5 \mathrm{mg} / \mathrm{kg}$ for locomotor activity. LSP2-9166 was first diluted into water at $20 \mathrm{mg} / \mathrm{ml}, \mathrm{pH}$ was adjusted to 7.4 and final concentration was set at 2 or $5 \mathrm{mg} / \mathrm{ml}$ using phosphate-buffered-saline (PBS). LSP2-9166 (2 or $5 \mathrm{mg} / \mathrm{kg}$, i.v.) or vehicle (PBS) was administered $15 \mathrm{~min}$ before each SA session.

\section{Surgery and cocaine operant self-administration}

All rats went through an i.v. catheterization procedure for operant SA, performed as described in detail previously [32]. Rats were anesthetized by an intraperitoneal injection (2 $\mathrm{ml} / \mathrm{kg}$ ) of a mixture containing ketamine (Imalgene 1000, $90 \mathrm{mg} / \mathrm{kg}$, Centravet) and xylazine (Rompun, $10 \mathrm{mg} / \mathrm{kg}$; Centravet) to perform surgical implantation of a chronic indwelling catheter in the right jugular vein. Catheters were flushed daily with heparin $(100 \mathrm{U} / \mathrm{mL})$ and ampicillin $(50 \mathrm{mg} / \mathrm{mL})$ to prevent clotting and infection. Animals were then housed individually. Following a 7-day recovery period, rats were submitted to behavioral experiments conducted during the dark period. Each operant chamber was equipped with two $2.5 \mathrm{~cm}$-diameter holes, $4 \mathrm{~cm}$ above the floor. Holes were selected as active (delivering cocaine), and inactive (without programmed consequence), and counterbalanced across groups. When the required number of active nose-pokes was reached, cocaine $60 \mu \mathrm{L}$ was delivered [32]. For molecular studies, rats followed a fixed ratio (FR) 1 schedule of reinforcement (cocaine, $0.33 \mathrm{mg} / \mathrm{kg} /$ injection, $2 \mathrm{~h} / \mathrm{session} / 10 \mathrm{~d}$ ) concurrently with saline control rats. For the pharmacological study, rats were first trained for $2 \mathrm{~h}$ daily sessions under FR1 (3d) and FR5 (6d) and then submitted to a PR schedule, in which the number of nosepokes required to earn an injection escalated within the session. Rats were trained for 6 consecutive daily sessions before the pharmacological treatment with LSP2-9166 or vehicle (5d). Each session lasted for 5h or until animals did not achieve the ratio for delivery of an injection within $1 \mathrm{~h}$. The breaking point to extinguish SA behavior was determined in each animal.

\section{Horizontal locomotor activity}

Locomotor activity was measured in individual dedicated home-cages with two infrared light beams. Numbers of longitudinal crossings were counted in 5 min bins. Three groups of rats implanted with catheters were processed (vehicle/ $\mathrm{NaCl}$; vehicle /Cocaine; 
LSP/Cocaine). Rats were first habituated to the actimetry cages and injections (vehicle) (3d). Following habituation to the cages (1h), rats received either LSP2-9166 (5 mg/kg, i.v.) or vehicle, and locomotor activity was recorded for $15 \mathrm{~min}$. Then rats received cocaine $(1.5$ $\mathrm{mg} / \mathrm{kg}$, iv) or $\mathrm{NaCl} 0.9 \%$, and activity was recorded for $1 \mathrm{~h}$.

\section{Brain sample dissection and quantitative real-time PCR}

Animals were given an overdose of pentobarbital (182 mg/kg, i.p.), 24h following the last SA session, brains were removed and sliced (1-mm coronal brain matrix, Harvard apparatus, MA, USA). Structures of interest were collected [33] (see Figure 2). Samples were frozen on dry ice and kept at $-80^{\circ} \mathrm{C}$. Total RNA was extracted using Ribozol (VWR, France). Reverse transcription was performed on $750 \mathrm{ng}$ of total RNA, with iScript (iScript ${ }^{\mathrm{TM}} \mathrm{cDNA}$ Synthesis Kit, Biorad, France). Real-time PCR was performed in triplicate using a CFX96 Touch $^{\mathrm{TM}}$ apparatus and Sso Advanced ${ }^{\mathrm{TM}}$ Universal SYBR Green supermix (Biorad, France). Thermal cycling parameters were $30 \mathrm{sec}$ at $95^{\circ} \mathrm{C}$ followed by 40 cycles of $5 \mathrm{sec}$ at $95^{\circ} \mathrm{C}$ and $45 \mathrm{sec}$ at $60^{\circ} \mathrm{C}$. Primer sequences: Rplp0 Fw CTGCCCGAGCCGGTGCCATC, Rv TTCAATGGTACCTCTGGAG ; Grm4, Fw TCCAGGACCAACGGACACTT Rv ACGTGACCATCAGCAGCATG ; Grm7 Fw AGACACAGAAGGGAACGCCT, Rv TCGGTTCTCATTGGGCCTCT. Expression levels were normalized to rplp0 housekeeping gene levels and compared between saline and treated samples using the $2^{-\Delta \Delta \mathrm{Ct}}$ method [34].

\section{Statistical analysis}

All results are expressed as mean \pm sem. Data from qPCR were analyzed using unpaired student's t-test. Data from SA experiments were analyzed using repeated measures ANOVAs with group as between-subject factor and treatment and session as within-subject factors. Data from locomotor activity experiments were analyzed using ANOVA with group as between-subject factor and bin as within-subject factor. The ANOVAs were followed by a Tukey HSD posthoc test when required. Significance was set at $p \leq 0.05$ (Statistica v13).

\section{Results}

\section{Effect of cocaine on $m G l u 4$ and $m G l u 7$ receptor gene expression}

We first examined whether voluntary cocaine intake would modulate mGlu4 and mGlu7 receptor gene expression in reward-related brain structures. Following 10 days of cocaine SA (2h/d/FR1), rats displayed a stable level of cocaine intake (>100 
injections/session) and directed more than $90 \%$ of the nose-pokes onto the active hole (data not shown). Rats receiving saline did not differentiate between holes $(37.8 \pm 1.34 \%$ in the active hole). Microdissected brain samples were processed to measure gene expression levels by qPCR (Figure 2). Both mGlu4 and mGlu7 transcripts were detectable, with a higher expression (> 2-fold) of mGlu7 compared to mGlu4 in NAc, PFC and HPC, as previously described $[12,13]$ (data not shown). Expression of both transcripts were significantly higher in cocaine- compared to saline-treated animals in NAc (Figure 2B) (Grm4 p=0.0011; Grm7 $p=0.0005)$ and HPC (Figure 2D) (Grm4 p=0.0023; Grm7 p=0.0047). A significant decrease was observed for mGlu4 in Amy (Figure 2E) (Grm4 p=0.0024) while no regulations were observed for mGlu7 in Amy and for both receptors in PFC (Figure 2A) and DS (Figure 2C).

\section{Effect of LSP-9166 on cocaine motivation}

We performed cocaine SA under a PR schedule of reinforcement (see methods). Treatment with LSP2-9166 (0, 2 or $5 \mathrm{mg} / \mathrm{kg}$ i.v.) began $15 \mathrm{~min}$ before each session, for 5 days. The choice of the doses was based on preliminary experiments and literature [26, 27, 35]. Several SA sessions were necessary for the rats to display stable behavior, the ANOVA analysis showing no statistical difference between sessions 5 and $6[\mathrm{~F}(1,38)=5.36, p=0.97]$ (Figure 3A). Therefore, statistical analysis was performed on data from the last two sessions of each treatment (sessions 5/6 and sessions 10/11). The ANOVA (treatment, group, session) revealed a significant treatment effect $[\mathrm{F}(1,38)=6.97, p=0.012]$ and a significant treatment $\mathrm{x}$ group interaction $[\mathrm{F}(2,38)=3.66, p=0.035)]$, without significant effect of the sessions nor interaction between session and the other factors. Tukey HSD posthoc test showed that rats receiving vehicle or LSP2-9166 $2 \mathrm{mg} / \mathrm{kg}$ did not display any behavioral changes in comparison to baseline (vehicle, $p=0.97$ and LSP2-9166 $2 \mathrm{mg} / \mathrm{kg} p=0.99$ ). In contrast, administration of LSP2-9166 $5 \mathrm{mg} / \mathrm{kg}$ resulted in a significant reduction in the breaking point $(p=0.004)$. We noted similar results for the active nose-pokes (treatment $\mathrm{x}$ group interaction, $\mathrm{F}(2,38)=5$, $p=0.012)$, with significant difference between baseline and LSP2-9166 $5 \mathrm{mg} / \mathrm{kg}(p<0.001)$. A global decrease was observed for the inactive nose-poke (significant treatment effect, $\mathrm{F}(1,38)=5, p=0.016)$ but without any significant group effect $(p=0.69)$, suggesting a motivational rather than a motor effect of the compound (Figure 3B).

\section{Effect of LSP-9166 on locomotor activity}

We then evaluated the effect of LSP2-9166 (5 mg/kg) on spontaneous locomotor activity (first injection) and on cocaine-induced hyperlocomotion (second injection) (Figure 3C). 
Following the first injection (bin 60-75), the ANOVA revealed a significant interaction (bin $\mathrm{x}$ treatment, $\mathrm{F}(6,72)=2.24, p=0.049)$. Locomotor activity increased only in vehicle $/ \mathrm{NaCl}$ and vehicle/Cocaine groups (bin 60-65, $p<0.0002$; LSP/Cocaine, $p=0.75$ ) (Tukey HSD test). No significant differences were observed between the 3 groups for all the bins (60-75). This indicates that LSP2-9166 reduced spontaneous activity-induced by the injection. For the second injection (bin 75-135) a significant interaction (bin $\mathrm{x}$ group $\mathrm{F}(24,288)=3.03$, $p=$ 0.000006) was observed. The Tukey HSD posthoc analysis showed a significant increase of locomotor activity in all three groups compared to their baseline (bin 75-80 $p<0.0004$ ). A significant difference was observed at bin 80 between vehicle/Cocaine and the two other groups $(p<0.002)$, suggesting a reduction of cocaine-induced locomotor activity in presence of LSP2-9166. No significant differences were observed between the 3 groups for the other bins of the analyzed period. These results indicated a global hypolocomotor activity induced by LSP2-9166.

\section{Discussion}

In this study, we show that voluntary cocaine intake induces an increase of mGlu4 and mGlu7 receptor transcripts in NAc and HPC. The orthosteric agonist LSP2-9166 inhibits the motivation to obtain the drug in a PR schedule of reinforcement, although this ligand induces a hypolocomotor effect. An increasing interest has emerged in the addiction field directed to mGlu receptors, which are well known to regulate glutamatergic neurotransmission [36, 37]. Group III mGlu receptor ligands were developped, with LSP1-2111 [29], an agonist for mGlu4, and AMN802 [18], acting as the first allosteric mGlu7 agonist. Recently, the orthosteric LSP2-9166 efficaciously decreased expression and reinstatement of a morphine CPP in mice [26] as well as ethanol consumption, motivation for ethanol and reacquisition of ethanol SA following abstinence in rats [27]. Our hypothesis that such modulatory effects may be expanded to cocaine behavioral responses has been tested here and we confirm a reduced motivation for drug taking in an operant paradigm.

Our results on locomotor activity have to be taken into account in the interpretation of the effects of LSP2-9166 on the motivation for cocaine. We observed a decreased spontaneous locomotor activity following a single injection of LSP2-9166 and a reduction in cocaine-induced hyperlocomotion. Interestingly, hypolocomotor effect of acute LSP2-9166 was previously reported in rats [27], at high doses in mice [26], with a small transient inactive state resembling catalepsy [35], with no effect on motor coordination in this latter study. Also 
no difference was detected on circular locomotor activity or rotarod test following systemic injection of LSP2-9166 (10 mg/kg ip,14 d) [35]. In addition, it did not impact other behaviors like sucrose intake or spatial memory [26, 27], suggesting a moderate locomotor impact on behavior. Moreover, mice deficient for mGlu4 receptor showed a higher basal locomotor activity [38], and mGlu7 receptor knockout mice presented a significant reduction of amphetamine-induced hyperlocomotor activity [39], compared with wild-type animals. Also, activation of mGlu7 receptors by AMN802 decreased activity in rodents [21,22] whereas no effect on locomotor activity was reported following LSP1-2111, a mGlu4 receptor orthostetic agonist, used at a lower dose [17]. In addition, anxiety may play a role in the effect of LSP29166 on cocaine-induced behavior, as it is known that a higher level of anxiety may decrease the motivation for cocaine in a PR paradigm [40]. Both anxiogenic and anxiolytic effects of LSP2-9166 have been described, at a high dose in mice [26], and following chronic LSP29166 treatment in rats [35], respectively. Altogether, such effect may depend on the dose and the species under study and we can not exclude any impact in our paradigm.

We show here that voluntary cocaine intake increased both Grm4 and Grm7 in NAc and HPC, whereas a decrease was observed for Grm4 in the Amy. These regulations may play a direct role on motivation (NAc) counterbalanced by an increase in anxiety (Amy). Such adaptations may participate to a global homeostatic regulation following cocaine intake, that involves complex neuronal circuitry.These regulations are region-specific as no modification were detected in the PFC or DS. Also, they were observed following $10 \mathrm{~d}$ of cocaine intake, $24 \mathrm{~h}$ after the last drug exposure, suggesting that they do not result from short term effects of cocaine. It would be of crucial interest to evaluate whether these regulations are long-lasting, reversible and whether they occur at distinct stages of addiction (withdrawal, seeking events), to highlight changes that could specifically mediate active drug seeking. No data are yet available on the regulation of these receptors by other drugs of abuse, at the protein level.

In our conditions, the breaking point under a PR schedule was reduced, indicating that the LSP2-9166 compound was able to reduce the motivational properties of cocaine. Our results are in accordance with previous publications showing that AMN082 reduces cocaine intake under a PR schedule of reinforcement [19]. Nevertheless, the neurobiological mechanisms involved in these effects are still not clear. The LSP2-9166 reduced cocaine reward-related effects probably through attenuation, via group III mGlu receptors activation, of the hyperglutamatergic state. Indeed, LSP2-9166 was demonstrated to be highly potent at mGlu4 $\left(\mathrm{EC}_{50}=0.06 \mu \mathrm{M}\right)$ and $\mathrm{mGlu} 7\left(\mathrm{EC}_{50}=2.2 \mu \mathrm{M}\right)[25]$ receptors. By increasing the 
activity of mGlu4/7 located in presynaptic terminals of glutamatergic afferents coming from the PFC, Amy and/or HPC, LSP2-9166 may lower glutamate release. Consequently, this would decrease the strength of goal-directed behavior to obtain the drug. Another hypothesis would be that the effects of LSP2-9166 are mediated by a reduction of GABA release on NAc neuronal targets, such as ventral pallidum and/or pars reticulata of the substantia nigra. Indeed, activation of group III mGlu receptors is able to weaken GABA neurotransmission, for instance in globus pallidum [14]. Future electrophysiological or neurochemical studies will investigate these effects on cocaine-induced glutamate and/or GABA neurotransmission.

The LSP2-9166 ligand also blocked morphine CPP expression and reinstatement after extinction [26]. Noticeably, it was more efficient in Hajasova et al.'s study since effects were already observed at lower doses $(0.5 \mathrm{mg} / \mathrm{kg}$, ip). The explanations for such discrepancies are still unclear and may be related to differences in species, behavioral paradigms, and/or the nature of the drug studied. Another explanation could be that mGlu receptors form heterodimers that may strongly modify the ligand affinity, as very recently described for mGlu2/7 receptors [28], or their constitutive activity, for mGlu4/7 [28, 41]. Such molecular interactions could occur between mGlu4/7 in specific reward-related brain structures, in a distinct manner depending on the drugs of abuse, and thus participate to the different effective doses observed between the studies.

\section{References}

[1] P.W. Kalivas, N.D. Volkow, The neural basis of addiction: a pathology of motivation and choice, Am J Psychiatry 162 (2005) 1403-1413.

[2] E.L. Gardner, What we have learned about addiction from animal models of drug selfadministration, Am J Addict 9 (2000) 285-313.

[3] M.D. Scofield, J.A. Heinsbroek, C.D. Gipson, Y.M. Kupchik, S. Spencer, A.C. Smith, et al., The Nucleus Accumbens: Mechanisms of Addiction across Drug Classes Reflect the Importance of Glutamate Homeostasis, Pharmacol Rev 68 (2016) 816-871.

[4] L.A. Knackstedt, P.W. Kalivas, Glutamate and reinstatement, Current Opinion in Pharmacology 9 (2009) 59-64.

[5] Y. Mihov, G. Hasler, Negative Allosteric Modulators of Metabotropic Glutamate Receptors Subtype 5 in Addiction: a Therapeutic Window., The international journal of neuropsychopharmacology 19 (2016) pyw002.

[6] J.T. Gass, M.F. Olive, Glutamatergic substrates of drug addiction and alcoholism, Biochem Pharmacol 75 (2008) 218-265.

[7] J. Peters, P.W. Kalivas, The group II metabotropic glutamate receptor agonist, LY379268, inhibits both cocaine- and food-seeking behavior in rats., Psychopharmacology 186 (2006) 143-149. 
[8] J.M. Aultman, B. Moghaddam, Distinct contributions of glutamate and dopamine receptors to temporal aspects of rodent working memory using a clinically relevant task., Psychopharmacology 153 (2001) 353-364.

[9] G.A. Higgins, T.M. Ballard, J.N.C. Kew, J.G. Richards, J.A. Kemp, G. Adam, et al., Pharmacological manipulation of mGlu2 receptors influences cognitive performance in the rodent., Neuropharmacology 46 (2004) 907-917.

[10] R. Crupi, D. Impellizzeri, S. Cuzzocrea, Role of Metabotropic Glutamate Receptors in Neurological Disorders., Frontiers in molecular neuroscience 12 (2019) 20.

[11] F. Nicoletti, R. Orlando, L. Di Menna, M. Cannella, S. Notartomaso, G. Mascio, et al., Targeting mGlu Receptors for Optimization of Antipsychotic Activity and DiseaseModifying Effect in Schizophrenia., Frontiers in psychiatry 10 (2019) 49.

[12] C. Corti, L. Aldegheri, P. Somogyi, F. Ferraguti, Distribution and synaptic localisation of the metabotropic glutamate receptor 4 (mGluR4) in the rodent CNS., Neuroscience 110 (2002) 403-420.

[13] C.M. Kosinski, S. Risso Bradley, P.J. Conn, A.I. Levey, G.B. Landwehrmeyer, J.B. Penney, et al., Localization of metabotropic glutamate receptor 7 mRNA and mGluR7a protein in the rat basal ganglia., The Journal of comparative neurology 415 (1999) 266284.

[14] N. Macinnes, S. Duty, Group III metabotropic glutamate receptors act as heteroreceptors modulating evoked GABA release in the globus pallidus in vivo., European journal of pharmacology 580 (2008) 95-99.

[15] O. Valenti, M.J. Marino, M. Wittmann, E. Lis, A.G. DiLella, G.G. Kinney, et al., Group III metabotropic glutamate receptor-mediated modulation of the striatopallidal synapse., The Journal of neuroscience : the official journal of the Society for Neuroscience 23 (2003) 7218-7226.

[16] L. Mao, J.Q. Wang, Distinct inhibition of acute cocaine-stimulated motor activity following microinjection of a group III metabotropic glutamate receptor agonist into the dorsal striatum of rats, Pharmacol Biochem Behav 67 (2000) 93-101.

[17] M. Zaniewska, E. Przegaliński, M. Filip, A. Pilc, D. Doller, Inhibitory actions of mGlu4 receptor ligands on cocaine-, but not nicotine-, induced sensitizing and conditioning locomotor responses in rats., Pharmacological reports : PR 66 (2014) 205-211.

[18] K. Mitsukawa, R. Yamamoto, S. Ofner, J. Nozulak, O. Pescott, S. Lukic, et al., From The Cover: A selective metabotropic glutamate receptor 7 agonist: Activation of receptor signaling via an allosteric site modulates stress parameters in vivo, Proceedings of the National Academy of Sciences 102 (2005) 18712-18717.

[19] X. Li, J. Li, X.-Q. Peng, K. Spiller, E.L. Gardner, Z.-X. Xi, Metabotropic Glutamate Receptor 7 Modulates the Rewarding Effects of Cocaine in Rats: Involvement of a Ventral Pallidal GABAergic Mechanism, Neuropsychopharmacology 34 (2009) 17831796.

[20] A. Bahi, The selective metabotropic glutamate receptor 7 allosteric agonist AMN082 prevents reinstatement of extinguished ethanol-induced conditioned place preference in mice, Pharmacology Biochemistry and Behavior 101 (2012) 193-200.

[21] M.C. Salling, S. Faccidomo, C.W. Hodge, Nonselective suppression of operant ethanol and sucrose self-administration by the mGluR7 positive allosteric modulator AMN082, Pharmacol Biochem Behav 91 (2008) 14-20.

[22] A. Palucha, K. Klak, P. Branski, H. van der Putten, P.J. Flor, A. Pilc, Activation of the mGlu7 receptor elicits antidepressant-like effects in mice, Psychopharmacology 194 (2007) 555-562. 
[23] R.M. O'Connor, J.F. Cryan, The effects of $\mathrm{mGlu}_{7}$ receptor modulation in behavioural models sensitive to antidepressant action in two mouse strains., Behavioural pharmacology 24 (2013) 105-113.

[24] K.A. Pelkey, X. Yuan, G. Lavezzari, K.W. Roche, C.J. McBain, mGluR7 undergoes rapid internalization in response to activation by the allosteric agonist AMN082., Neuropharmacology 52 (2007) 108-117.

[25] F. Acher, J.-P. Pin, C. Goudet, A. Eschalier, J. Busserolles, D. Rigault, et al., Hypophosphorous acid derivatives having antihyperalgic activity and biological applications thereof, (2012).

[26] Z. Hajasova, C. Canestrelli, F. Acher, F. Noble, N. Marie, Role of mGlu7 receptor in morphine rewarding effects is uncovered by a novel orthosteric agonist, Neuropharmacology 131 (2018) 424-430.

[27] S. Lebourgeois, C. Vilpoux, J. Jeanblanc, F. Acher, N. Marie, F. Noble, et al., Pharmacological activation of mGlu4 and mGlu7 receptors, by LSP2-9166, reduces ethanol consumption and relapse in rat, Neuropharmacology 133 (2018) 163-170.

[28] C.H. Habrian, J. Levitz, V. Vyklicky, Z. Fu, A. Hoagland, I. McCort-Tranchepain, et $a l$., Conformational pathway provides unique sensitivity to a synaptic mGluR, Nat Commun 10 (2019) 5572.

[29] C. Selvam, I.A. Lemasson, I. Brabet, N. Oueslati, B. Karaman, A. Cabaye, et al., Increased Potency and Selectivity for Group III Metabotropic Glutamate Receptor Agonists Binding at Dual sites, J Med Chem 61 (2018) 1969-1989.

[30] D.B. Kastrinsky, P. Kumar, G.A. Marriner, C.E. Barry III, A convergent synthesis of chiral diaminopimelic acid derived substrates for mycobacterial L,D-transpeptidases, Synthesis 44 (2012) 3043-3048.

[31] A.H.G. Siebum, W.S. Woo, J. Raap, J. Lugtenburg, Access to any site-directed isotopomer of methionine, selenomethionine, cysteine, and selenocysteine - Use of simple, efficient modular synthetic reaction schemes for isotope Incorporation, Eur. J. Org. Chem. (2004) 2905-2913.

[32] P. Romieu, L. Host, S. Gobaille, G. Sandner, D. Aunis, J. Zwiller, Histone deacetylase inhibitors decrease cocaine but not sucrose self-administration in rats, J Neurosci 28 (2008) 9342-9348.

[33] G. Paxinos, C. Watson, The rat brain in stereotaxic coordinates, (2007).

[34] K.J. Livak, T.D. Schmittgen, Analysis of relative gene expression data using real-time quantitative PCR and the 2(-Delta Delta C(T)) Method, Methods 25 (2001) 402-408.

[35] B. Girard, P. Tuduri, M.P. Moreno, S. Sakkaki, C. Barboux, T. Bouschet, et al., The mGlu7 receptor provides protective effects against epileptogenesis and epileptic seizures, Neurobiol Dis 129 (2019) 13-28.

[36] J. Cartmell, D.D. Schoepp, Regulation of Neurotransmitter Release by Metabotropic Glutamate Receptors, Journal of Neurochemistry 75 (2002) 889-907.

[37] M.S. D'Souza, Glutamatergic transmission in drug reward: implications for drug addiction, Frontiers in Neuroscience 9 (2015) 404.

[38] Y.A. Blednov, D. Walker, E. Osterndorf-Kahanek, R.A. Harris, Mice lacking metabotropic glutamate receptor 4 do not show the motor stimulatory effect of ethanol, Alcohol 34 (2004) 251-259.

[39] N.M. Fisher, R.W. Gould, R.G. Gogliotti, A.J. McDonald, H. Badivuku, S. Chennareddy, et al., Phenotypic profiling of mGlu7 knockout mice reveals new implications for neurodevelopmental disorders, Genes Brain Behav (2020).

[40] D.E. Bush, F.J. Vaccarino, Individual differences in elevated plus-maze exploration predicted progressive-ratio cocaine self-administration break points in Wistar rats, Psychopharmacology (Berl) 194 (2007) 211-219. 
[41] P.J. Kammermeier, Constitutive activity of metabotropic glutamate receptor 7, BMC Neurosci 16 (2015) 17.

\section{Figure Captions}

Figure 1. Optimization of LSP2-9166 synthesis. Reagents and conditions: (i) $\mathrm{NH}_{4} \mathrm{H}_{2} \mathrm{PO}_{2}$ (2.5 eq), Et 3 B (1 eq), $\mathrm{O}_{2}, \mathrm{MeOH}, \mathrm{RT}, 30 \mathrm{~min}, 2$ times; (ii) tert-butyl 2-(4-formyl-2(trifluoromethoxy)phenoxy) acetate (1 eq), $N, O$-bis(trimethylsilyl) acetamide (BSA) (4 eq), degassed $\mathrm{CH}_{2} \mathrm{Cl}_{2}$, RT, $24 \mathrm{~h}$; (iii) a) $3 \mathrm{M}$ aqueous $\mathrm{HCl}$, THF, RT, $48 \mathrm{~h}$; b) C-18 flash chromatography. Bu: butyl; Boc; tert-butoxycarbonyl; BSA: N,O-bis(trimethylsilyl)acetamide; eq: equivalent; RT: room temperature.

Figure 2. Cocaine effect on mGlu group III receptor gene expression. Transcript levels for Grm4 and Grm7 genes were examined by qPCR in PFC (A, 7-8/group), NAc (B, 79/group), DS (C, 6-8/group), HPC (D, 5-10/group) and Amy (E, 6-8/group) following cocaine SA. Bars represent mean \pm SEM fold change vs saline group for each receptor. $*^{*} p<0.01$; $* * * p<0.001$. Samples were dissected with large $(3 \mathrm{~mm})$ or small $(1.9 \mathrm{~mm})$ punchers as indicated.

\section{Figure 3. Effect of LSP2-9166 on cocaine-self administration and locomotor} activity. Effect of LSP2-9166 ( 2 and $5 \mathrm{mg} / \mathrm{kg}$ i.v., $15 \mathrm{~min}$ before the operant session) on cocaine SA in a progressive ratio (PR) schedule of reinforcement. Number of injections (A) and number of nose-pokes $(\mathbf{B})$ are presented across all sessions. Results are expressed as mean \pm SEM for each group (vehicle, $\mathrm{n}=18$; LSP2-9166, 2mg/kg, n=8; LSP2-9166, 5mg/kg, $\mathrm{n}=15) . * * p<0.01$, baseline (S5/S6) vs treatment (S10/S11) of LSP2-9166 5mg/kg. Locomotor activity (C) was recorded following habituation (1h), i.v. injection of LSP2-9166 (5 mg/kg, iv) or vehicle (bin 60-75), and then cocaine (1.5 mg/kg) or $\mathrm{NaCl} \mathrm{0.9 \%} \mathrm{(bin} \mathrm{75-135);}$ (vehicle/NaCl $\mathrm{n}=8$; vehicle/cocaine $\mathrm{n}=10 ; \mathrm{LSP} 2-9166 /$ cocaine $\mathrm{n}=9$ ). $* * * p<0.001$ vehicle/cocaine vs LSP/cocaine at bin 80 .

\section{Aknowledgments}

This project was supported by the Université de Strasbourg, the Centre National de la Recherche Scientifique (CNRS) and by the « Innovation thérapeutique pour les maladies mentales » (ITMM CNRS). DN and CC received a PhD fellowship from the French Ministère de l'Enseignement Supérieur et de la Recherche". DN received a 4th year PhD funding from 
Fonds Paul Mandel. We thank C Correia, Dr MC Olmstead and Dr F Noble for fruitful discussions and careful reading of the manuscript, Dr A Barbelivien for statistical advices. The authors declare no conflict of interest.

\section{Author's contribution}

PR, JZ, KB conceived the study and wrote the paper. PR, DN, CQ, DF performed the experiments. PR, DN, RB, KB analyzed the data and designed the figures. FA and IMT designed and synthesized the mGlu compound. All authors approved the final version of the manuscript. 